\title{
Teacher education accreditation in Turkey: The creation of a culture of quality
}

\author{
Gary M. Grossman ${ }^{a}$, Margaret K. Sands ${ }^{b, *}$, Barbara Brittingham ${ }^{c}$ \\ a Arizona State University, USA \\ ${ }^{\mathrm{b}}$ Bilkent University, 06800, Bilkent, Ankara, Turkey \\ ${ }^{\mathrm{c}}$ New England Association of Schools and Colleges, Bedford, MA, USA
}

\section{A R T I C L E I N F O}

\section{Keywords:}

Teacher education

Accreditation

Educational reform

\begin{abstract}
A B S T R A C T
Turkey's experience in developing and piloting accreditation criteria and national standards for teacher education is examined. The full implementation of an accreditation process for teacher education programs was not completed within the time of the development project. However, the effort to do so encouraged the formation of a 'quality culture' in the faculties of education. The paper discusses what took place and analyses the later response of teacher educators to the introduction of accreditation criteria and the way in which they were introduced. Educators largely welcomed national standards and accreditation, but wished to have flexible means of implementation.
\end{abstract}

(c) 2009 Elsevier Ltd. All rights reserved.

\section{Context}

\subsection{Introduction}

Education, particularly teacher education, has been of importance in Turkey since the establishment of the Republic (Dewey, 1983). Many previous studies have also established the concern given to education, from the words and actions of Mustafa Kemal Atatürk in 1923 (Mango, 2004), to present day expenditure (HenTov, 2004), to public policy reforms (Dundar and Lewis, 1999). Studies related to prospective membership of the European Union (Grossman and Onkol, 2006) have been particularly relevant.

Education was the thrust of the National Education Development Project (NEDP) between 1991 and 1999. The NEDP was a Turkish Government World Bank project of some \$100 million US that featured two major components. The first was a reform of elementary and secondary education schooling in terms of infrastructure, textbooks, and educational management. The second, which began in late 1994, was an expansion and transformation of the national system of teacher education, focusing primarily on pre-service curriculum development and training fellowships. It was driven by an emphasis on teaching methodologies and work in schools to update the older model which emphasized subject content, with virtually no time in schools (Sands and Özçelik, 1998).

\footnotetext{
* Corresponding author. Tel.: +90 312290 2924; fax: +90 3122664065 .

E-mail addresses: Gary.Grossman@asu.edu (G.M. Grossman), msands@bilkent.edu.tr (M.K. Sands), Barbara_Brittingham@yahoo.com (B. Brittingham).
}

Related to the second component of the NEDP were two further developments. The first was the restructuring of Turkish faculties of education, aimed at enhancing the professional development of pre-service educators. The second was the preparation and piloting of an accreditation model for education faculties.

The two components of the NEDP were administered by different entities in the Turkish governing structure. The elementary and secondary school project was located in, and managed by, the Ministry of National Education (MONE). The pre-service teacher education project was governed by the Higher Education Council (HEC).

It is the HEC pre-service teacher education project which forms the basis of the discussion here. The paper examines the introduction of new standards of accreditation into the dynamic environment that characterized Turkish teacher education in the late 1990s. The consequences of the work, and the diversity of opinion among Turkish teacher educators, were the subjects of research four years later, funded by a Fulbright grant. The research was a comprehensive examination of the reform in teacher education in Turkey during this period. The data for the present paper as well as three previous papers (Grossman and Onkol, 2006; Grossman et al., 2007; Grossman and Sands, 2008) come from this research.

\subsection{The Turkish Higher Education Council and teacher education}

In Turkey, the Higher Education Council (HEC), which was established in 1982, is responsible for the university system. Among other functions, it determines the requirements for the promotion of academic staff and the standards for university degrees. For faculties and graduate schools of education, it also 
defines in some detail the structure of teacher education programs leading to qualified teacher status. The length of each program, the number of credits, the titles of courses, and a summary of the content of the courses which constitute a teacher education program, plus the qualification the program leads to, are all laid down by the HEC.

The HEC has therefore established all the teacher education programs that currently exist in Turkey, and continues to develop and modify them as necessary. In this broad sense, HEC can be said to standardize teacher education. By being permitted by HEC to open a teacher education department and by conforming to what is laid down, faculties of education are recognized nationally, and their graduates accepted as qualified teachers.

A countrywide national system of standards and accreditation of universities and of departments within universities, regardless of subject area, is not yet in place. In 1997-1998 HEC made a study of general accreditation issues in universities, and a feasibility study was undertaken by the British Council (1998). Some faculties or departments in professional fields, usually in the English-medium universities, and especially engineering and business faculties, have become accredited by overseas bodies. Section 1.4 gives more details. Such a link with international accreditation organizations has not occurred in education faculties. In fact, accreditation issues in general have not been able to be widely addressed in the context of a rapidly growing number of education faculties aimed at producing teachers for a young population.

There is a system of inspector visits to universities. The inspectors are sent by HEC. However, their brief is not to evaluate teaching or research, but rather to work with university administrators and ensure that rules and regulations are being followed, both at central university level and within faculties. For example, they examine the qualifications of students entering higher degree programs, assess the transfer of students between universities, check the records of faculty boards and other university committees to establish the legality of the decisions taken and their conformity with the rules, consider student numbers within programs, check budget expenditure, and such other matters.

\subsection{Reasons for the present situation}

The lack of a nation-wide system of formal accreditation and updating of standards may be due to a number of factors. Perhaps foremost among them is the large and very rapid increase in the number of Turkish universities. There were some 18 established state-run universities in 1992. By 2009 there were 94 state universities, and 9 private universities (HEC, 2009).

This expansion of university provision has caused a dilution of the number of well-qualified senior academic staff in established universities as they move to take up senior posts in the new universities, and new younger colleagues are appointed to both old and new universities. Many education faculties, which metamorphosed from teaching colleges when teaching became an allgraduate profession in 1992, had lecturers without doctoral degrees who were inherited from this older system. Further, education faculties have to deal with very large numbers of students. Many have had years of two-shift working, one shift consisting of regular students during the day, the other of evening classes catering to a second tuition-paying group. Such pressures of work, with large teaching loads, concentrate the attention of faculty inwards and reduce the time available for discussion and liaison outside more immediate tasks.

Another reason, perhaps accounting in part for the lack of exchanges between universities of ideas and good practice, is that academics tend to remain in the same university, often from their graduation through MA and $\mathrm{PhD}$ to faculty appointment. There is therefore a lack of faculty mobility between universities and thus of experience of standards and practices elsewhere.

Beyond this, there are no professional groups of subject-area academics such as science educators meeting regularly to discuss and to exchange ideas and good practice. Of course, academics in Turkey from various universities meet each other at conferences, but there the emphasis is on the presentation of research papers, rather than the discussion and exchange of current trends in the education and training of teachers. Moreover, there is little or no emphasis on teacher educators themselves having teaching experience in primary or secondary schools, so experience of accreditation of schools by, for example, CIS, or the international recognition of school programs such as the International Baccalaureate is lacking.

Within Turkish universities, there is an extensive system of peer review for academic promotion from assistant to associate to full professor, with external evaluators. There is also a jury system for higher degrees which involves committees of up to five academics, with the required participation of one or more from another university. There is not, however, an external monitoring system which examines or evaluates student progress and achievement as undergraduate students pursue their studies. As a consequence, there is some experience among more senior faculty of standards in parallel institutions from their higher degree work. But for most, exchange between faculty members from different universities on such issues as quality control, qualitative and quantitative performance indicators, staff development, other models of leadership and management, or various ways toward achieving school effectiveness, does not regularly occur.

\subsection{Cultures of quality internationally}

As higher education becomes more important for the success of individuals and economies, countries around the world are establishing the means to ensure the quality of institutions of higher education and the degree programs they offer. Ensuring quality is a rapidly growing field in international higher education. The International Network of Quality Assurance Agencies in Higher Education (INQAAHE) was established in 1991 at a meeting attended by representatives from ten countries (Lewis, 2006). Fifteen years later, in 2006, there were 100 full members from 60 countries. By 2008, there were 148 full members from 75 countries. The international interest in quality assurance and accreditation is also reflected in the UNESCO Global Forum on International Quality Assurance, Accreditation and the Recognition of Qualifications (UNESCO, 2008; Stella, 2006) and the Global University Network for Innovation (2007).

Quality assurance systems generally have four components: a set of standards that programs or institutions must meet; a selfstudy report prepared by the program or institution being reviewed; a review process by experts; and a report which usually leads to a decision (Morse, 2006). The accountability, or quality assurance, function of the agencies is accomplished by publishing a list of approved institutions and programs. Thus, the interests of prospective students, employers, and funding bodies are served (Heusser, 2006).

The details of the systems, and the extent to which they are tightly held by, or independent of, government vary greatly from country to country. The features, focus, and relationship with government are highly influenced by the history and culture in which they operate (Brittingham, 2009). For example, for some countries, such as the United Arab Emirates, quality assurance agencies were formed to oversee new private universities in a country that had previously had only government institutions. Other countries, such as Ireland, developed such functions to stimulate state institutions of higher education by providing a 
system of external review. In the Irish technical higher education sector, the agency which was first developed to review statefunded programs now also reviews new entrants from the private sector.

Countries undertaking systematic quality assurance have much to learn from each other. In this respect, INQAAHE is the major international gathering place for professionals in the field. There are smaller regional gatherings as well: in Europe, Asia-Pacific, Latin America, Africa, and among Arab countries. In 2007, the World Bank funded the Global Initiative on Quality Assurance Capacity (GIQAC). Administered through UNESCO, the GIQAC makes grant awards to regional and international organizations of quality assurance agencies, with an emphasis on those in developing countries, to build and strengthen quality assurance in higher education.

In European countries, quality assurance processes were given a boost by the Bologna process. The cooperation and sharing involved is seen in quality assurance circles by the founding in 2000 of the European Network of Quality Assurance Agencies (ENQA).

One important goal of quality assurance systems is to move beyond an episodic review process in which the university or program focuses on the standards only in the time immediately preceding its next review. The goal is to move to an internalizing of the standards and a commitment to improvement, sometimes referred to as a 'culture of quality.' This dimension was emphasized by the Conference of Ministers in their 2003 Berlin Communiqué, in which they noted that the internal responsibility for quality assurance is central to universities being able to retain and enhance their autonomy. (Berlin Communiqué, 2003)

As quality assurance functions develop, they tend to become more elaborate and therefore more time-consuming and expensive. They also tend to move from quantitative bright-line decisions (those which describe objectively a clearly defined standard with little or no room for varying interpretation) to more nuanced qualitative standards, shifting the emphasis from accountability to enhancement. With this development, the potential gain for programs and institutions is also strengthened. In its second survey of quality procedures in the European higher education area, ENQA found an increasing emphasis not simply on quality assurance but also on quality improvement (Costes et al., 2008).

To support such endeavours, universities may set up a specialized office or function to gather the data and analyze it, to assist in faculty development and setting targets, plus other initiatives leading to improvement. By promoting a culture of quality, departments and universities focus on continuing progress, not simply on attaining verification that standards are met. The University of Bahrain, for example, is developing a quality assurance ethos in its various colleges, connecting with international accrediting groups where available, and developing internal capacity for goal setting, self-evaluation, and analysis.

In Turkey, evidence of a culture of quality is perhaps seen most clearly in the field of engineering. ABET, the American accreditor of engineering programs, recognized that engineering is a field with clear international dimensions. Given global business demands, the need for multinational firms to hire engineers prepared in one country to work on projects funded by another and perhaps operating in a third is real and can only grow. ABET began a program of recognizing substantial equivalence-an assurance that engineers prepared in country A, B, or C had followed a program on which employers and graduates could rely. In 1993-1994, two Turkish universities applied for and gained substantial equivalence designations from ABET (Ergüder, 2006). By 2005, 41 engineering programs from four universities had gained such status. In 2001, the engineering deans in Turkey formed their own council (MDK) and by 2002, they had established their Engineering Evaluation Board (MÜDEK). By 2008, MÜDEK had accredited 37 programs in seven universities. The work is overseen by an independent body on which there are representatives of universities (though sitting deans are not included), the Union Chambers of Engineers and Architects (TMMOB), industry, and the Turkish Society for Quality (KalDer).

The interest within higher education for quality assurance processes is also reflected at the institutional level. Starting in 1997, Turkish universities, at a rate of about two per year have been applying to participate in the European Universities Association's quality assurance process. By 2008, 21 universities had participated in the process. It is worth noting that in both engineering and the institutional review, universities participate of their own accord. They are not required to do so by government.

Even if such activities are not required, internal motivation to participate in quality assurance and accreditation activities is considerable (Gift and Bell-Hutchinson, 2007). International validation is often a key factor. Such validation may make it easier to attract key faculty, ease cross-border education of students, or gain research grants and contracts. Accreditation can also be seen as a means of improvement. When the standards appear high and in line with the institution's mission, and the process promises feedback from respected peers, actually going through accreditation can be as attractive as the status to be earned.

Validation of claims can also be a motivating factor. Institutions claiming to offer American-style education, for example, often seek American accreditation in part as a way to demonstrate that they, unlike their unaccredited neighbors, are genuine in their claim.

Competition is another motivator. A university which is accredited, or programs which are approved or accredited, suggest that the institution is better than others. A university which wishes to reinforce an internal culture of quality may set up internal mechanisms or centres to assist in improvement and provide regular requirements which focus developments on areas identified as important nationally or internationally. This and the repeated participation in external reviews helps develop, support, and reinforce an internal culture of quality.

\section{Setting up a system of accreditation in Turkish faculties of education: the role of the NEDP}

HEC utilized the structure of the on-going NEDP pre-service teacher education project to set up a comprehensive study on standards in faculties of education. It also piloted a means of accrediting faculties of education in a nation-wide exercise which involved all faculties and the training of teacher educators from those faculties.

The process began with a study-visit of senior academics and HEC personnel to the UK and US in May 1998 to investigate:

- national criteria for teacher education courses/programs

- accreditation for teacher education courses

- parties associated with accreditation

- the relationship between accreditation and certification

- maintaining national standards: quality assurance, monitoring, and inspection.

Two international accreditation experts were appointed, one each from the US (National Council for Accreditation of Teacher Education-NCATE) and the UK (Her Majesty's Inspectors) to come to Ankara. They, together with the project team, worked with an 
Accreditation Working Party composed of 13 academics from faculties of education around Turkey. A book on standards and accreditation was drafted, following discussions between the experts, project team, and all faculties. It gave full details of the standards expected in faculties of education and how accreditation visits should be conducted. Members of the Working Party were trained in the conduct and procedures of such accreditation visits.

The proposed system was piloted in 1999. Visits to six faculties of education took place after each had submitted its self-evaluation reports for review by the Accreditation Working Party. Two or three programs in each faculty of education were surveyed, ranging from pre-school education to secondary science and mathematics. In all, 15 programs were reviewed. The pilot work was followed by a national conference in 1999, where 100 representatives of all 43 faculties of education discussed the findings of the accreditation visits and the materials produced by the Accreditation Working Party. The accreditation book was published later that year (Brittingham et al., 1999).

Subsequently, nine dissemination-training courses were held across the country, with 433 participants from the 43 participating faculties of education. Thirty-six senior teacher educators were trained as assessors. The Accreditation Working Party was enlarged, and received further training in the UK and US in order to enhance their technical expertise.

The accreditation system was therefore ready for implementation by HEC, a nation-wide system of accreditation for the programs delivered in faculties of education having been established. It included 40 national standards for teacher education for every faculty that proposed, now or in the future, to train teachers, along with the means to certify the standing of each program. The 36 trained assessors trained 366 program heads from all faculties in the accreditation process and the application of standards.

So, by the end of the NEDP pre-service teacher education project in mid-1999, not only were the goals of the pre-service teacher education reform implemented (Grossman et al., 2007) and the national system of faculties of education restructured (Grossman and Sands, 2008), but also an accreditation system was built which could serve both the present and future faculties of education.

As a result of this work, by the turn of the century, teacher educators in Turkish faculties of education understood that accreditation was being discussed at a national level. It could help to ensure the quality of future teachers, and provide clear guidelines as to the expectations of HEC in administering teacher education programs.

The accreditation process in faculties of education has not been pursued in the decade since. However, the more compelling question is not necessarily if the establishment of a nation-wide system of accreditation was achieved. Rather, the issue is whether there exists in Turkish teacher education a culture of quality that can sustain efforts to improve teacher education in general in the future. That is the issue this paper considers.

\section{Research problem}

A nation-wide cadre of stakeholders in a quality assurance movement was created as described above. As Wagenaar (2006) suggests, a key issue, perhaps the main one, in developing a successfully implemented accreditation is the creation of the culture of quality discussed earlier. A critical question for Turkey's future in quality assurance in teacher education is, therefore, not just the experience in 1999 of initiating and attempting to set up a top-down regulation of the education faculties. It may rather be the extent to which the culture of quality has developed so that future efforts can also include bottom-up strategies. Indeed, one of the purposes of training the program heads from all teacher education faculties was so that they could start to engage their colleagues in a dialogue to recognize the need for quality standards in teacher training.

One question, therefore, which concerns us is how well these dialogues succeeded. Is there, in Turkey today, a culture within the teacher education community that recognizes the need for a national system of quality assurance? If so, what do educators think should be the nature of that system? Is it the job of a national governmental unit to impose the standards on which quality is built, or do teacher educators themselves feel empowered to develop such a system? Further, what should be the relationship, with regard to quality assurance, between the national governing bodies and the education faculties? Finally, in Turkey, schools and university faculties of education are controlled by different organizational bodies (MONE and HEC respectively). Is there a feeling among teacher educators that quality control in teacher education could progress more smoothly if there were a change in this situation?

The initiative of 1998-2000 represented a good start in the national accreditation process of Turkish faculties of education. The momentum at that time was high, and the extent to which there is a consensus in favour of a national system of quality standards is still very much to the point. The following examines, through research data, the views of educators in the faculties of education on this topic.

\section{The Fulbright study: methodology}

The study of Turkish teacher educators was undertaken in 2003 and 2004 with a Fulbright grant. A three-part multi-method survey was used to gather the opinions of full-time university academics (assistant professors, associate professors, and full professors) from the education faculties of 54 state universities in Turkey. Due to the size of the population from which a sample would be drawn, and the fact that all prospective respondents had access to and regularly used relatively modern information and communications technologies, it was determined that a computerized self-administered questionnaire (CSAQ) would be used for the initial phase (Phase I) of the study (Babbie, 2008). The contact was made through a selection process by which approximately one-third of the qualifying academics were randomly selected for the sample $(N=457)$. Of these, $170(37 \%)$ agreed to take part in the study after a maximum of three follow-up contacts. While there is not a large literature regarding response rates in CSAQ studies, the response rate of Phase I was generally in conformity with what one expects in selfadministered studies utilizing other modalities, such as mail (Miller and Salkind, 2002). This sample was given an internet-based survey instrument in Turkish with 82 questions including both scaled response and open-ended questions (Grossman and Sands, 2008).

From those who replied, 38 teacher educators were randomly selected to receive a long and in-depth discussion of teacher education issues on the telephone (Phase II). Due to the fact that these respondents had already agreed to participate in the earlier phase of the study, all of the 38 agreed to participate (response rate $=100 \%$ ). Many of the difficulties usually associated with telephone surveys were therefore obviated (Miller and Salkind, 2002; Dillman, 1978). Finally, seven leaders of teacher education departments and faculties, such as deans and department heads, were surveyed to examine the views of senior faculty on these issues (Phase III). Generally, the data collected from the survey were structured for quantitative analysis and were intended for descriptive and inferential statistical analysis, although qualitative data were collected and will be examined in forthcoming studies.

The on-line questionnaire was given an expert review from five senior bilingual teacher educators, who had been actively involved in the reforms, from one of the leading teacher education faculties 
Table 1

Characteristics of Turkish teacher educators from 54 state universities.

\begin{tabular}{|c|c|c|c|c|c|}
\hline Characteristics & Age range & $\%$ & $N$ & Mean & SD \\
\hline \multicolumn{6}{|l|}{ Geographical region } \\
\hline 1. Marmara (Istanbul area) & & 18.3 & 32 & & \\
\hline 2. Aegean (Izmir area) & & 13.6 & 23 & & \\
\hline 3. Mediterranean (Antalya area) & & 5.3 & 9 & & \\
\hline 4. Southeastern Anatolia (Diyarbakir area) & & 1.8 & 3 & & \\
\hline 5. Central Anatolia (Ankara-Kayseri area) & & 36.7 & 62 & & \\
\hline 6. Eastern Anatolia (Van area) & & 8.9 & 15 & & \\
\hline 7. Black Sea (Samsun-Trabzon area) & & 15.4 & 26 & & \\
\hline Age range & $28-65$ & & & 42.9 & 8.53 \\
\hline Full professors & & 9.4 & 33 & & \\
\hline Associate professors & & 10.6 & 18 & & \\
\hline Assistant professors & & 59.4 & 101 & & \\
\hline Other positions & & 10.6 & 18 & & \\
\hline Duration of position title for six years or fewer & & 61.8 & 105 & & \\
\hline Duration of position title for longer than six years & & 38.2 & 65 & & \\
\hline Employed at same university more than 12 years & & 43.5 & 74 & & \\
\hline Employed at same university $6-12$ years & & 32.4 & 55 & & \\
\hline Employed at same university fewer than six years & & 24.1 & 41 & & \\
\hline Speak at least one foreign language fluently & & 53.5 & 91 of these & & \\
\hline 1. English & & 75.6 & 69 & & \\
\hline 2. German & & 11.1 & 10 & & \\
\hline 3. French & & 5.6 & 5 & & \\
\hline Speak two or more foreign languages fluently & & 7.7 & 13 & & \\
\hline
\end{tabular}

Grossman and Sands (2008).

Table 2

Item 56: How familiar are you with the effort over the past several years to establish national standards and accreditation practices in teacher education?

\begin{tabular}{lrr}
\hline & $\%$ & $N$ \\
\hline Very familiar & 25.7 & 43 \\
Somewhat familiar & 48.5 & 81 \\
Not very familiar & 24.0 & 40 \\
Not familiar at all & 1.8 & 3 \\
& 100.0 & $n=167$ \\
\hline
\end{tabular}

Mean $=2.04$, S.D. $=.81$ all summative percentages rounded to $100.0 \%$.

in Ankara. The questionnaire was changed according to their feedback. They also worked on the Turkish translation of the questionnaire to ensure the linguistic equivalence of the instrument (Miller and Salkind, 2002) before it was placed on-line.

Both English and Turkish versions of the questionnaire were tested through the utilization of the equivalent-form method of reliability. Teacher educators who used both English and Turkish in their work completed both versions of the questionnaire. Any item not yielding a correlation of at least $r=.85$ was eliminated from the instrument (Zikmund, 2006).

\section{Results}

Those who participated in the collection of data numbered 170 . According to their academic rank, the size of their faculty, and their location in Turkey, they were representative of the teacher education population in Turkey, because the percentages of all subdivisions were similar to those overall. Their details are given in Table 1.

Incidentally, the survey discerned a particular aspect of Turkish academic life, namely the high degree of employment stability found in Turkish universities. Far more often than is the case in other countries, young people working as graduate assistants in Turkey remain with the same university as they are promoted in their academic career. It is still the norm to find relatively young academics who have worked for 10 years or more in the same university.

The survey included several items relating to accreditation. The items are reproduced and analyzed in Tables 2-4.

Table 2 shows that a sizeable number of the respondents, threequarters of the sample, indicated that they had considerable or some familiarity with the national developments in accreditation and the establishment of standards for teacher education programs.

Table 3 shows that, regardless of whether or not they had participated in the accreditation movement, almost all respondents (93\%) appreciated the need for national standards and an accreditation system.

Similarly, Table 4 shows that most respondents (87\%) agreed that national standards would be useful for teacher education programs.

Table 3

Item 57: Whether or not you are aware of such efforts, which would be nearest to your position regarding attempts to establish national standards and accreditation for teacher education in Turkey?

\begin{tabular}{|c|c|c|}
\hline & $\%$ & $N$ \\
\hline $\begin{array}{l}\text { 1. It is imperative that mandatory national standards and accreditation } \\
\text { criteria are established to ensure quality in how teachers are trained in education faculties. }\end{array}$ & 55.9 & 95 \\
\hline $\begin{array}{l}\text { 2. Accreditation for teacher training should be established but teacher-training } \\
\text { programs should be free to choose how they meet these accreditation criteria. }\end{array}$ & 37.1 & 63 \\
\hline 3. National standards are useful but accreditation criteria for teacher training are unnecessary. & 5.9 & 10 \\
\hline \multirow[t]{2}{*}{ 4. Neither national standards nor accreditation criteria are necessary in Turkey. } & 1.2 & 2 \\
\hline & 100.0 & $n=170$ \\
\hline
\end{tabular}

Mean $=1.52$, S.D. $=.66$. 
Table 4

Item 69: A clear set of national standards in teacher education would be beneficial for the teacher-training program in my university.

\begin{tabular}{lrr}
\hline & $\%$ & $N$ \\
\hline 1. Strongly agree & 27.7 & 47 \\
2. Somewhat agree & 59.4 & 101 \\
3. Neither agree nor disagree & 8.2 & 14 \\
4. Somewhat disagree & 4.7 & 8 \\
5. Strongly disagree & 0.0 & 0 \\
& 100.0 & $n=170$ \\
\hline
\end{tabular}

Mean $=1.88$, S.D. $=.70$.

A National Committee of Teacher Education was set up in 1998, based at HEC, charged with the development of teacher education. Its responsibilities included setting up national criteria for accreditation and teacher education programs, developing national standards for newly qualified teachers, assisting in the maintenance and control of the quality of teacher education programs, and working for the dissemination of good practice and the pursuit of excellence.

By 2004 when the study was done, we would expect that the National Committee and its work would be known to faculty in teacher education programs. Table 5 , however, shows that the work of the National Committee was not well known in the faculties of education.

While the program heads who were trained by the project to lead the accreditation movement may have failed to familiarize their colleagues in the fullest detail, Table 2 shows that there was still a good level of awareness among teacher educators about developments in national standards and accreditation. Having said this, the presence of a significant minority (37\% in Table 3 ) within the Turkish teacher educator culture of quality who regard these standards as being desirable but applied more flexibly is intriguing. It indicates a divergence of opinion within the teacher education community as to what the character of that culture should be. To explore this point, the three points in Tables 6-8 were examined. Table 6 shows the overall response to a question which posited accreditation either as compulsory or as a support mechanism.

Almost two-thirds (63.3\%) of the respondents in Table 6 preferred Option 1, namely that accreditation should be used to evaluate teacher education programs, and that it should be a necessary prerequisite before an institution could offer programs leading to qualified teacher status. Tables 7 and 8 explore further the positions indicated in Table 6 .

Teacher educators, having supported Option 1 in Table $6(63 \%)$ came out strongly in Table 7 (67\%) in favour of the enforcement of national standards by a national agency responsible for accrediting Turkish teacher education institutions. At the same time (Table 8) $91 \%$ of them wanted to be allowed some flexibility in actually delivering the standards.

As a final consideration, the study examined the breadth and depth of this culture of quality. To truly constitute such a culture of quality, one would expect to see evidence of it across the board in all categories and ranks of the teacher education community. It would not be the province of any one subgroup. Accordingly, the

Table 5

Item 70: Are you aware of the National Committee of Teacher Education (NCTE)?

\begin{tabular}{lrr}
\hline & $\%$ & $N$ \\
\hline 1. Yes & 30.9 & 52 \\
2. No & 69.0 & 116 \\
& 100.0 & $n=168$ \\
\hline
\end{tabular}

Mean $=1.69$, S.D. $=.46$
Table 6

Item 58: Select the answer that comes closest to representing how you think accreditation criteria should be administered.

\begin{tabular}{|c|c|c|}
\hline Is your position: & $\%$ & $\mathrm{~N}$ \\
\hline 1. Much closer to Option 1 than Option 2 & 35.4 & 56 \\
\hline 2. Somewhat closer to Option 1 than Option 2 & 20.9 & 33 \\
\hline 3. Slightly closer to Option 1 than Option 2 & 7.0 & 11 \\
\hline 4. Equally close to Option 1 and Option 2 & 10.8 & 17 \\
\hline 5. Slightly closer to Option 2 than Option 1 & 16.5 & 26 \\
\hline 6. Somewhat closer to Option 2 than Option 1 & 8.2 & 13 \\
\hline \multirow[t]{2}{*}{ 7. Much closer to Option 2 than Option 1} & 1.3 & 2 \\
\hline & 100.0 & $n=158$ \\
\hline
\end{tabular}

Mean $=2.82$, S.D. $=1.82$

Option 1: Accreditation must ensure that students trained as teachers in Turkish education faculties receive equivalent qualifications, regardless of the institution they attend. That is, anyone receiving a teaching credential should be expected to have had certain classes, a significant exposure to relevant teaching methods, and a certain level of practical experience in student teaching. Anyone not receiving such training should not be allowed to teach in Turkish classrooms. Likewise, those teacher education programs that do not provide such training should not be allowed to train teachers. Therefore, the administration of national accreditation criteria should be primarily an evaluative function by which education faculties are permitted to provide teacher education programs.

Option 2: Accreditation should serve to assist education faculties in Turkish universities to improve themselves such that students trained as teachers receive equivalent qualifications, regardless of the institution they attend. Teacher education programs that do not currently meet such accreditation criteria should receive help and support to achieve this goal. Students trained in teacher education programs receiving such assistance should still be allowed to teach, regardless of the accreditation status of the teacher education programs they attend. Therefore, the administration of national accreditation criteria should be primarily a support function by which education faculties receive help in improving teacher-training programs

Table 7

Item 59: National standards should be enforced by a central national accreditation authority.

\begin{tabular}{lrr}
\hline & $\%$ & $N$ \\
\hline 1. Strongly agree & 27.4 & 46 \\
2. Somewhat agree & 39.3 & 66 \\
3. Neither agree nor disagree & 20.8 & 35 \\
4. Somewhat disagree & 10.7 & 18 \\
5. Strongly disagree & 1.8 & 3 \\
& 100.0 & $n=168$
\end{tabular}

Mean $=2.20$, S.D. $=1.02$

'Characteristics of Turkish teacher educators' (Table 1) were tested against the variable identified in Table 4 , 'A clear set of national standards in teacher education would be beneficial for the teachertraining program in my university'. The latter was chosen as being the variable most clearly indicative of recognition of the value of quality criteria. Table 9 presents zero-order product-moment correlation (Pearson's $r$ ) values.

The data from Table 9 do not challenge the notion that the culture of quality in Turkey is widespread throughout the profession.

\section{Table 8}

Item 60: Teacher education programs should be held to national standards in training teachers, but allowed flexibility in how those standards are achieved.

\begin{tabular}{lrr}
\hline & $\%$ & $N$ \\
\hline 1. Strongly agree & 30.4 & 51 \\
2. Somewhat agree & 60.7 & 102 \\
3. Neither agree nor disagree & 3.5 & 6 \\
4. Somewhat disagree & 4.7 & 8 \\
5. Strongly disagree & 0.6 & 1 \\
& 100.0 & $n=168$ \\
\hline
\end{tabular}

Mean $=1.85$, S.D. $=1.85$ 
Table 9

Zero-order correlation coefficient values between factors related to characteristics of the sample and acknowledgement of the need for a 'culture of quality' in Turkish teacher education.

\begin{tabular}{lc}
\hline & $r$ Value (*sig. at .05) \\
\hline Geographical region & -.049 \\
1. Marmara (Istanbul area) & -.006 \\
2. Aegean (Izmir area) & $.194^{*}$ \\
3. Mediterranean (Antalya area) & .024 \\
4. Southeastern Anatolia (Diyarbakir area) & .014 \\
5. Central Anatolia (Ankara-Kayseri area) & -.048 \\
6. Eastern Anatolia (Van area) & -.088 \\
7. Black Sea (Samsun-Trabzon area) & .013 \\
Age & .061 \\
Rank & .104 \\
Duration of position title & -.063 \\
Employment at same university & .081 \\
Fluency in a foreign language & \\
\hline
\end{tabular}

Despite one factor showing statistical significance (Mediterranean region), the correlation is quite weak, if indeed it is meaningful at all. As there is no logical reason to suggest that the teacher educators in the Mediterranean region uniquely differ from their colleagues across the country, we can probably safely disregard this.

\section{Discussion}

The data in Tables 2-4 show a strong constituency for national standards and accreditation in teacher education. Three-quarters (74\%, Table 2) of the sample were aware of efforts made in this area, and 93\% (Table 3 ) recognized the need for standards of quality assurance. The data in Table 3 however indicate some degree of disagreement with how those standards would be enforced. This by no means undermines the point that national standards are broadly found desirable, a point strongly made in Table 4 where a large majority (87\%) of the sample called for national standards in teacher education. While it is somewhat surprising that a quarter (26\%) of the sample knew little or nothing about the work which had been done in this direction (Table 2), and only slightly more (31\% in Table 5) knew specifically about the existence of the National Committee of Teacher Education, the more compelling finding is the apparently strong sense among teacher educators that quality standards are necessary, but lacking.

The results in Tables 6-8 also show that teacher educators support the idea of national standards which should be used by a national accrediting agency to evaluate teacher education programs and place a seal of approval on them. The accreditation process should be essential for institutions which offer programs leading to qualified teacher status.

Clearly, the data in Tables 3,4 , and 6-8 show only a disagreement regarding the degree of enforcement of quality standards, not whether they should exist. There is very little disagreement as to the fact that there should be standards, while suggesting that the Turkish culture of quality generally regards some flexibility as being valuable. The need for flexibility from Table 3 is reinforced in Table 8. However, while many agree with the notion of flexibility, the rather large standard deviation shown in Tables 6 and 8 suggests considerable reservation about how much flexibility would be appropriate. Whether or which, the constituency for a culture of quality appears to exist among Turkish teacher educators.

\section{Conclusion}

Teacher educators across Turkey have clearly embraced a culture of quality supportive of accreditation, despite some disagreement between them about how the process is to be done, and despite lack of follow up after the pilot projects and accreditation training courses in 1999. They have become aware of developments in accreditation and quality standards, particularly of developments in the United States and UK, and they recognize the usefulness of, and the need for, such a system in their own faculties. The Higher Education Council could continue the professional advancement that was made through its National Education Development Project and begin the implementation of quality standards for teacher education in Turkey. Many of the professionals who were involved in that project would form a useful resource and, from the date presented above, welcome the move to a national system of accreditation.

\section{Acknowledgement}

The authors wish to thank Dr Necmi Akşit of Bilkent University for his comments on, and assistance with, the manuscript.

\section{References}

Babbie, E., 2008. The Basics of Social Research, fourth edition. Thomson-Wadsworth, Belmont, CA.

Berlin Communiqué, 2003. Realising the European Higher Education Area. Communique of the Conference of Ministers responsible for Higher Education, in Berlin on 19 September 2003. Available at http://www.eua.be/fileadmin user_upload/files/Quality_Assurance/OFFDOC_BP_Berlin_communique_final. 1066741468366.pdf.

British Council, 1998. The feasibility of establishing a system of quality assessment in universities in Turkey. Report to YÖK, Ankara.

Brittingham, B., 2009. Accreditation in the United States: how did we get to where we are? New Directions for Higher Education 145, 7-27.

Brittingham, B., Sands, M.K., Ardac, D., Ayas, A.P., Badavan, Y., Cephe, P.T., et al., 1999. Standards and Accreditation in Teacher Education in Turkey. YÖK, Ankara.

Costes, N., Crozier, F., Cullen, F., Grifoll, J., Harris, N., Helle, H., Hopbach, A., Kekäläinen, H., Knezevic, B., Sits, T., Sohm, K., 2008. Quality procedures in the European higher education area and beyond-second ENQA survey. ENQA Occasional Papers 14, European Network of Quality Assurance, Helsinki, Finland.

Dewey, J., 1983. Report and recommendations upon Turkish education. In: Boydston, J.A. (Ed.), The Middle Works: Essays on Politics and Society vol. 15 of Collected Works. Southern Illinois Press, Carbondale, pp. 1923-1924.

Dillman, D.A., 1978. Mail and Telephone Surveys: The Total Design Method. Wiley Interscience, New York.

Dundar, H., Lewis, D., 1999. Equity, quality and efficiency: effects of reform in Turkish higher education. Higher Education Policy 12, 343-346.

Ergüder, Ü., 2006. Accreditation and quality assurance in Turkey. In: Presentation at the 2006 International Commission Meeting, Council for Higher Education Accreditation, San Francisco, January.

Gift, S.I., Bell-Hutchinson, C., 2007. Quality assurance and the imperatives for improved student experiences in higher education: the case of the University of the West Indies. Quality in Higher Education 13, 145-157.

Global University Network for Innovation, 2007. Higher Education in the World 2007: Accreditation for Quality Assurance: What Is at Stake? Palgrave MacMillan, New York.

Grossman, G.M., Onkol, P.E., 2006. Towards the Europeanization of Turkish teacher education: education reform and professional development in a new context. In: Terzis, N.P. (Ed.), Lifelong Learning in the Balkans. Kyriakidis Brothers SA Thessaloniki, Greece, pp. 337-357.

Grossman, G.M., Onkol, P.E., Sands, M., 2007. Curriculum reform in Turkish teacher education: attitudes of teacher educators towards modernization in an EU candidate nation. International Journal of Educational Development 27, 138150.

Grossman, G.M., Sands, M.K., 2008. Restructuring reforms in Turkish teache education: modernization and development in a dynamic environment. International Journal of Educational Development 28, 70-80.

HEC, 2009. Üniversiteler. Available at http://www.yok.gov.tr/content/view/527/ 222/lang,tr_TR.

Hen-Tov, E., 2004. The political economy of Turkish military modernization. The Middle East Review of International Affairs 8 (4).

Heusser, R., 2006. Mutual recognition of accreditation decisions in Europe. Quality in Higher Education 12, 253-256.

Lewis, R., 2006. International trends in the quality assurance of higher education. In: Presentation at the 2006 International Commission Meeting, Council for Highe Education Accreditation, San Francisco.

Mango, A., 2004. The Turks Today. Overlook Press, New York

Miller, D.C., Salkind, N.J., 2002. Handbook of Research Design and Social Measurement. Sage Publications, Thousand Oaks, CA.

Morse, J.A., 2006. The INQAAHE guidelines of good practice for external quality assurance agencies: assessment and next steps. Quality in Higher Education 12 $243-252$ 
Sands, M.K., Özçelik, D.A., 1998. Work in Schools: Secondary. YÖK, Ankara.

Stella, A., 2006. Quality assurance of cross-border higher education. Quality in Higher Education 12, 257-276.

UNESCO Global Forum on International Quality Assurance, 2008. Accreditation and the recognition of qualifications, 2008. Available at: http://portal.unesco.org/
education/en/ev.php-URL_ID=41247\&URL_DO=DO_TOPIC\&URL_SECTION=201. html.

Wagenaar, R., 2006. Creating a Culture of Quality: Quality Assurance at the University of Gröningen in the Netherlands. Physica-Verlag HD/Springer, Berlin. Zikmund, W.G., 2006. Business Research Methods. Dryden Press, New York. 